\title{
Compound Heterozygous Niemann-Pick Type C Disease in The Neonatal Period
}

\section{Yenidoğan Döneminde Birleşik Heterozigot Niemann-Pick Tip C Hastalığı}

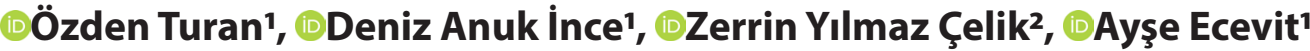

'Başkent University, Department of Pediatrics, Division of Neonatology, Ankara, Turkey

2Başkent University, Department of Medical Genetics, Ankara, Turkey

\section{Dear Editor,}

Niemann-Pick C Disease (NPC; OMIM \#257220 and OMIM \#607625) is a rare lysosomal lipid storage disorder. NPC is characterized by accumulation of unesterified cholesterol and glycosphingolipids in the lysosome and endosome. Disease is inherited in an autosomal recessive and caused by NPC1 or NPC2 genes. ${ }^{[1]}$ The wide clinical spectrum range from newborn to adulthood periods posses special problems for diagnosis Herein, we report a compound heterozygous NPC disease in the neonatal period.

A 34-year-old, gravida 3 mother delivered a male baby at $304 / 7$ of weeks gestation by cesarean section, with a birth weight of $2100 \mathrm{~g}$ ( $>90$ percentile) and an Apgar score of $7 / 9$ in the $1^{\text {st }}$ and $5^{\text {th }}$ minute, respectively. Parents were not consanguineous. A detailed prenatal ultrasonography showed hyperechogenic fetal bowel. Although first trimester combined screening test was high, parents did not accept amniocentesis.

His brother was born 34 2/7 weeks gestation and birth weight was 3070 g. ${ }^{[2]} \mathrm{He}$ had nonimmunhydrops fetalis and diagnosed NPC. He died on postnatal $52^{\text {nd }}$ day because of respiratory distress and progressive liver failure. The patient was born and followed up outside of our center.

$\mathrm{He}$ developed respiratory distress in the delivery room and was admitted to the neonatal intensive care unit. On admission, he had tachypnea, skin edema, hepatosplenomegaly, hypotonic and weak neonatal reflexes. At 1 hour of life he was intubated and mechanically ventilated due to respiratory failure. The patient's respiratory problems were due to prematurity. Initial laboratory findings were as follows: complete blood count, coagulation parameters and TORCH screen were normal. The blood and urinary levels of amino acids, organic acids and serum chitotriosidase activity were normal. The measurement of lysosomal sphingomyelinase activity was below in our case which was $4.06 \mathrm{nmol} / 17 \mathrm{~h} / \mathrm{mg}$ protein ( Normal: mean \pm SD: 7.73 \pm 3.08 ). Echocardiography showed a only patent foramen ovale. Results of abdominal ultrasonography showed hepatosplenomegaly and increased echogenicity. Thrombocytopenia (platelet count: $66 \times 10^{9} / \mathrm{L}$ ) and direct hyperbilirubinemia (total/ direct bilirubin: $15.8 / 3.1 \mathrm{mg} / \mathrm{dL}$ ) appeared on the 5th day of life. Placentomegaly (weight: $672 \mathrm{~g}$ ) and vacuolized cells (foamy macrophages in the stroma of terminal villi) were detected in the pathological examination of the placenta. The patient was discharged 40 days after the admission. We learned that the patient died at the age of 5 months due to sepsis.

The infant and our patient molecular genetic analysis were same: compound heterozygous for the deletion of c.1831_1836delGATGAA in exon 12 and c.3734_3735delCT in exon 24 of the NPC1 gene. The mother and father genetic analysis were respectively heterozygous for the deletion of c.1831_1836delGATGAA in exon 12 and c.3734_3735delCT in exon 24 of the NPC1 gene. Written informed consent was obtained from parents.

Presentation of NPC disease in the perinatal period is considerably limited. The prenatal clinical findings of NPC consisted of in utero hepatosplenomegaly, ascites, 
oligohydramnios and intrauterine growth restriction. ${ }^{[3]}$ Our patient was born with hepatosplenomegaly and preterm delivery. The most important factors in neonatal mortality are respiratory failure and progressive liver disease.

The pathologic examination of the placenta may be a key to the diagnosis. The presence of abnormal vacuolized cells in the placenta is highly suspicious for GM1 gangliosidosis or lysosomal storage disorder.

Knowing the genetic abnormality of the index case is important for the chance of prenatal genetic diagnosis and to have a healthy baby.

Keywords: Niemann-Pick Type C, NPC1, newborn

\section{ETHICAL DECLARATIONS}

Referee Evaluation Process: Externally peer-reviewed.

Conflict of Interest Statement: The authors have no conflicts of interest to declare.

Financial Disclosure: The authors declared that this study has received no financial support.

Author Contributions: All of the authors declare that they have all participated in the design, execution, and analysis of the paper, and that they have approved the final version.

\section{REFERENCES}

1. Sitarska D, Ługowska A. Laboratory diagnosis of the Niemann-Pick type $C$ disease: an inherited neurodegenerative disorder of cholesterol metabolism. Metab Brain Dis 2019;34:1253-60.

2. Surmeli-Onay O, Yakarisik S, Korkmaz A, et al. Prenatal-onset NiemannPick type $C$ disease with nonimmune hydrops fetalis. Pediatr Neonatol 2013;54:344-7.

3. Spiegel R, Raas-Rothschild A, Reish $O$, et al. The clinical spectrum of fetal Niemann-Pick type C. Am J Med Genet A. 2009;149:446-50. 